\title{
FISIOLOGÍA DE LA CICATRIZACIÓN CUTÁNEA
}

\author{
Physiology of cutaneous cicatrization
}

Fecha de recibido: 17-08-2010 • Fecha de aprobación: 30-10-2010

Resumen. Una herida es la consecuencia de una agresión, que da como resultado una solución de continuidad en los tejidos, cuando dicha lesión es de curso agudo, constituye una ulceración; si se extiende por más de tres semanas se denomina úlcera; al complejo proceso destinado a reparar los tejidos dañados se le conoce como cicatrización, el cual involucra un patrón fisiológico constante y por etapas solapadas, sin embargo, las heridas crónicas no siguen dicho patrón de reparación, en estas, dicha reparación se alcanza cuando se corrige la causa de la lesión y se trata el lecho de modo adecuado. La importancia del conocimiento de estos procesos biológicos radica en la capacidad de intervenir en sus diferentes etapas facilitando la resolución de la lesión, logrando la modificación del lecho de la herida.

Palabras clave: regeneración, cicatriz, reparación de heridas, epitelio.

Abstract. A wound is the result of aggression which produces a continuity solution in tissues. When it is an acute injury, it becomes ulceration; if it goes on for more than three weeks it is called ulcer. Cicatrization is a complex process aims at repairing a damaged tissue which involves a permanent physiological pattern and overlapped stages; however, chronic wounds do not follow this healing pattern. They reach healing when injury cause is eliminated and wound bed is properly treated. Importance of being aware of these processes lies in the intervention capacity in its different stages which facilitates the injury healing and achieving wound bed modification.

Key words: regeneration, cicatrix, epithelium, wound healing.

\section{INTRODUCCIÓN}

La piel es la barrera protectora contra el medio ambiente. La pérdida de su integridad como resultado de una lesión o enfermedad puede conducir a una discapacidad grave o incluso la muerte según su extensión o complicaciones agregadas no controladas, siendo millares de personas alrededor del mundo los afectados por diferentes tipos de lesiones agudas y crónicas.

El objetivo principal del conocimiento de los procesos fisiológicos de la cicatrización es favorecer un cierre rápido y obtener una cicatriz funcional y estéticamente satisfactoria. Los avances recientes en biología celular y molecular han ampliado enormemente la comprensión de los procesos biológicos implicados en la reparación de heridas y la regeneración tisular y han dado lugar a mejoras en el cuidado de heridas. Se revisa a continuación la biología de la curación de las heridas.

* Cirujano General, Coordinador Clínica de heridas y ostomias, Hospital Universitario de Neiva, Profesor Asistente, Universidad Surcolombiana. Correo electrónico: alfredoheridas@hotmail.com 


\section{HISTORIA}

El estudio de las características biológicas de la reparación tiene raíces históricas. Los primeros escritos médicos describen ampliamente el cuidado de las heridas, como es el caso del Papiro Smith (1770 a. C.). Los antiguos Egipcios, Griegos e Hindúes crearon métodos para tratar heridas y describieron los fundamentos de su tratamiento, resaltando la importancia de extraer cuerpos extraños, suturar y protegerlas con material limpio, de la acción de agentes corrosivos ${ }^{(1)}$.

Durante el siglo XIV, con el empleo de la pólvora, surge una nueva época del tratamiento de las heridas, reemplazando la actitud pasiva en la atención de las heridas por una postura más dinámica que promoviera la "curación de las heridas". En el siglo XVI se reescriben los métodos de tratamiento atraumático, que logran la cicatrización rápida y sin mayores complicaciones, siendo la introducción del fundamento de la tendencia actual, la asistencia atraumática, partiendo del principio que minimizar la lesión tisular permite la cicatrización rápida y eficaz ${ }^{(2)}$. En el siglo XIX, se alcanza el concepto de la interferencia mínima, es decir al eliminar todos los impedimentos para los procesos de cicatrización normales se culminaría con un mejor resultado ${ }^{(3)}$.

Sin embargo, la reparación no siempre culmina en un resultado perfectamente funcional y los procesos que generan potencia e integridad tisular, pueden ocasionar también estenosis fibrosas, enfermedad valvular, cirrosis, encarcelamientos de tendinosos, queloides, adherencias, entre otras anormalidades. El futuro esta entonces en hallar métodos que permitan controlar forma, tamaño y propiedades del tejido cicatricial, y surgiría así una nueva era en el tratamiento de las heridas lo cual evitaría fenómenos patológicos producto de la formación de cicatrices ${ }^{(4)}$.

\section{BIOLOLOGÍA TISULAR}

La piel está conformada por dos capas, la epidermis externa y la dermis subyacente ${ }^{(5)}$.

La epidermis tiene cinco estratos celulares, las células de la capa basal se reproducen constantemente y durante su envejecimiento se desplazan hacia la superficie, en donde se depositan y gracias a un proceso de transformación gradual cambian de células redondas y nucleadas en escamas planas y ricas en queratina, que se encuentran en las capas externas de la epidermis, las cuales están desvitalizadas; en la epidermis se encuentran estructuras especializadas como los folículos pilosos.

La dermis está conformada por fibras de colágeno y elastina en una matriz de mucopolisacáridos, irrigadas por una rica trama vascular y sostiene la epidermis; la elastina le aporta elasticidad y la colágena su fuerza tensil. El grosor y por tanto su tensión, varían según la zona corporal.

En la unión de la dermis y la epidermis se forma una serie de ondas llamadas pedículos radiculares o papilas. Bajo la dermis se encuentra el tejido hipodérmico de sostén, o tejido graso subcutáneo, el cual contiene nervios y sus terminales, vasos sanguíneos que irrigan la piel y linfáticos.

\section{HERIDA}

Es la región anatómica donde queda interrumpida la continuidad celular entendiéndose por una solución de continuidad de las cubiertas externas que lo protegen, como es el caso de los tegumentos, las capas de revestimiento mucoso o de la superficie o cápsula fibrosa de los órganos. Dicha lesión tisular es el común denominador de todo trauma y afecta al organismo en diversas formas, incluyendo pérdida local de fluidos, dolor por estímulos neurales y liberación de productos celulares a la circulación ${ }^{(6)}$.

En todas las heridas hay una alteración metabólica continua que dura semanas, meses o incluso años y la mayor parte de estas curan hasta lograr integridad tensil durante el periodo de balance nitrogenado negativo; el restablecimiento del metabolismo nitrogenado hacia el estado anabólico, tiene mayor importancia para recuperar la fuerza muscular y el vigor que para la curación de las heridas. El riesgo de sufrir una lesión o que dicha lesión se haga mayor, aumenta cuando se pierde la sensibilidad, ya que no se puede transmitir información sobre la proximidad o presencia de un peligro ${ }^{(7)}$.

\section{FISIOLOGÍA DE LA CICATRIZACIÓN}

La cicatrización es un proceso dinámico, interactivo en el cual participan mediadores solubles extracelulares, células sanguíneas, células de la matriz tisular, y del parénquima, para facilitar el estudio y comprensión del proceso de reparación de las heridas, se le ha dividido en fases ${ }^{(8)}$, las cuales ocurren de manera secuencial pero se 
superponen en el tiempo: "hemostasia", "inflamatoria", "proliferativa" o de "granulación", de "epitelización" y de "remodelación" (Figura 1).

\section{FASE I - HEMOSTASIA}

Una vez ocurre la lesión se produce el daño en los vasos sanguíneos con la consiguiente pérdida de plasma, células y factores hacia el intersti- cio. La hemostasia y coagulación se inicia con la activación de los elementos celulares de la sangre y lleva a la formación del coágulo o tapón hemostático, proceso en el cual interfiere la cascada de los factores de la coagulación y el fenómeno de agregación plaquetaria(9) (figura 2).

Inicialmente se adhieren las plaquetas al intersticio, donde la trombina y el colágeno fibrilar expuesto las activa, como resultado de esta acti-

\begin{tabular}{|l|}
\hline PROCESO DE \\
CICATRIZACIÓN \\
o Secuencia de \\
eventos \\
bioquímicos \\
complejos y \\
ordenados que \\
ocurren en \\
respuesta a las \\
lesiones \\
tisulares y \\
conducen a la \\
reconstrucción \\
del mismo. \\
\hline
\end{tabular}

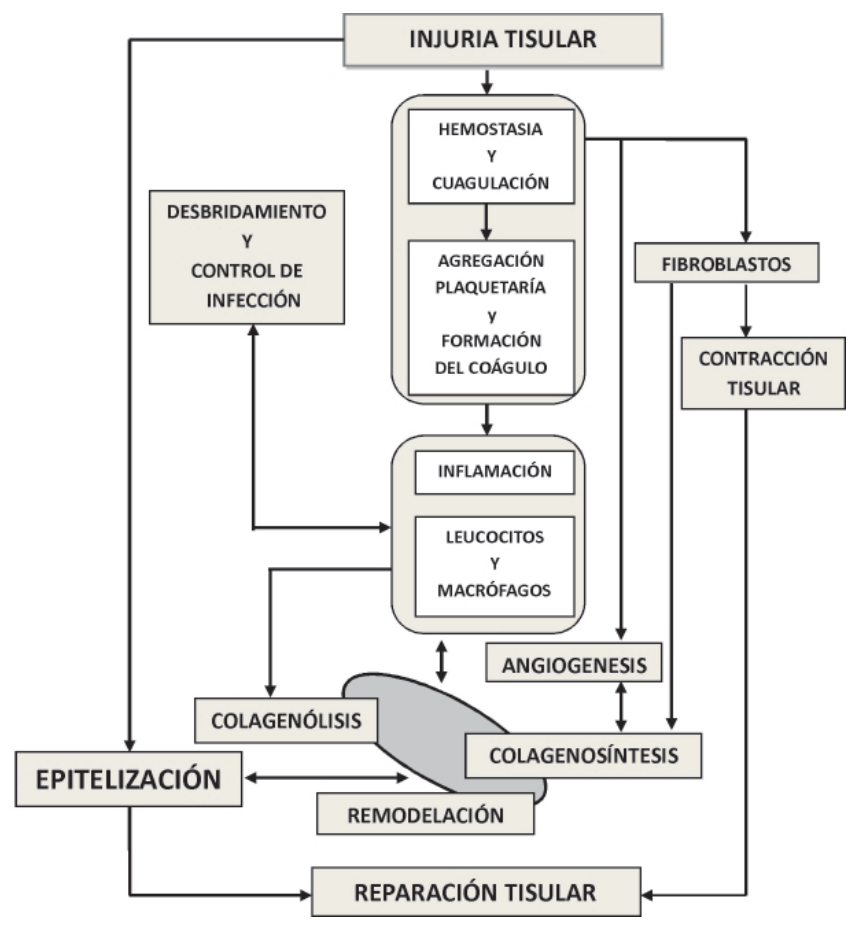

Figura 1. Fisiología de la cicatrización.
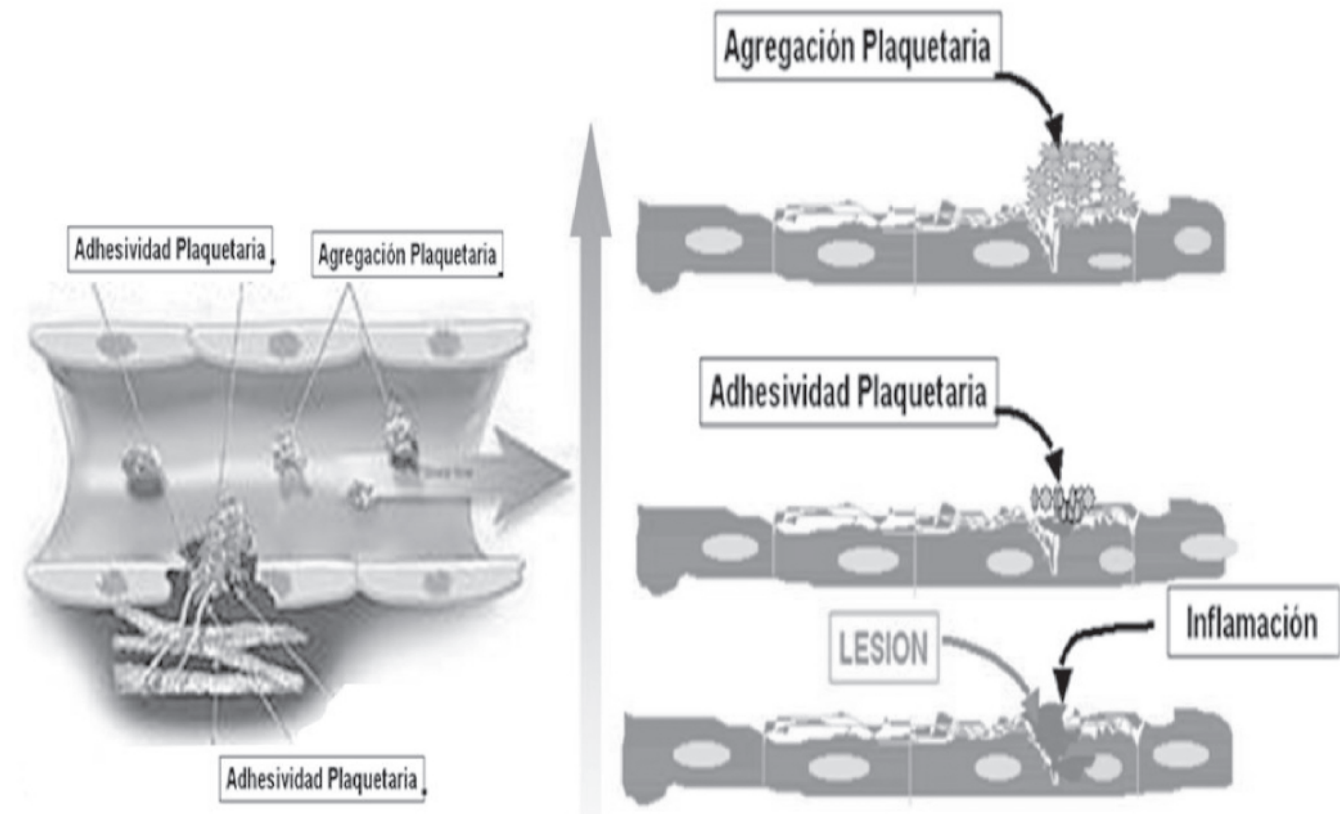

Figura 2. Fases de la hemostasia 
vación se produce su degranulación, liberando numerosos mediadores: entre ellos fibrinógeno, fibronectina y trombospondina que intervienen en la agregación plaquetaria, el factor VIII, de Von Willebrand que contribuye a la adhesión plaquetaria, actuando como puente de unión entre el colágeno subendotelial y el receptor plaquetario de integrina aIIb $\beta 3$ y el Adenosin difosfato y la trombina que atraen más plaquetas a la zona lesionada ${ }^{(10)}$. Todo esto da lugar a la agregación plaquetaria y a la formación de un tapón hemostático. Las plaquetas también sintetizan factores de crecimiento: el factor de crecimiento derivado de las plaquetas (PDGF) y el factor de crecimiento transformador- $\beta$ (TGF- $\beta$ ) con acción mitógena y quimiotáctica en los fibroblastos, el factor de crecimiento transformador- $\alpha$ (TGF- $\alpha$ ) y el factor de crecimiento epidérmico (EGF) estimulan la epitelización ${ }^{(11,12)}$ (figura 3).

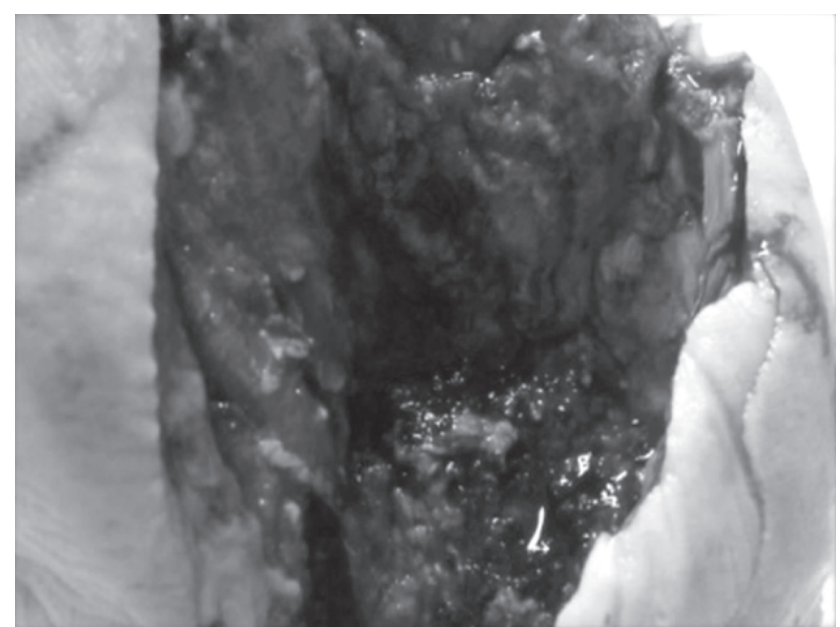

Figura 3. Detalle de herida en fase de hemostasia.

La formación de un coágulo producida por la cascada de coagulación que inician los elementos de la sangre y llevan a la formación de trombina, enzima que transforma el fibrinógeno en fibrina que promueve la coagulación además de activar las plaquetas ${ }^{(13,14)}$. El fibrinógeno y los receptores de superficie de las plaquetas se unen y se polimerizan para formar una matriz de fibrina, dando lugar a un trombo. El coágulo de fibrina y la fibronectina proveen una matriz inicial que favorece la migración de monocitos, fibroblastos y queratinocitos además de intervenir en la respuesta inflamatoria por medio de la bradiquinina y las fracciones C3a y C5a del complemento, los cuales aumentan la permeabilidad vascular y promueven la quimiotaxis de neutrófilos y monocitos ${ }^{(15,16)}$.
En forma simultánea el endotelio produce prostaciclina, que inhibe la agregación, lo cual limita el proceso, la antitrombina III, inhibe la formación de fibrina, la proteina $C$, inhibe al factor VIII y limita la adhesión y el activador del plasminógeno y la plasmina son relevantes en la lisis del coágulo ${ }^{(17,18)}$.

\section{FASE II - INFLAMATORIA}

Esta fase se caracteriza por la migración de neutrófilos a la herida, atraídos por factores quimiotácticos específicos, como el factor estimulador de colonias de granulocitos / macrófagos (GM-CSF), la kalikreina y los fibrinopéptidos, que aumentan la expresión del complejo dimérico CD11/CD18, facilitando la marginación vascular y la posterior diapédesis ${ }^{(19,20)}$. Una vez los neutrófilos migran al intersticio, se dan las interacciones "célula-célula" y "célula-matriz" favorecidas por las integrinas iniciando así la función de fagocitosis de bacterias y proteínas de la matriz por medio de liberación de enzimas específicas (hidrolasas, proteasas y lisozimas) y radicales libres de oxígeno ${ }^{(21)}$. Finalmente, los neutrófilos agotados quedan atrapados en el coágulo y se disecan con él, y los que permanecen en tejido viable mueren por apoptosis y posteriormente son removidos por los macrófagos o fibroblastos (22, 23) (figura 4).

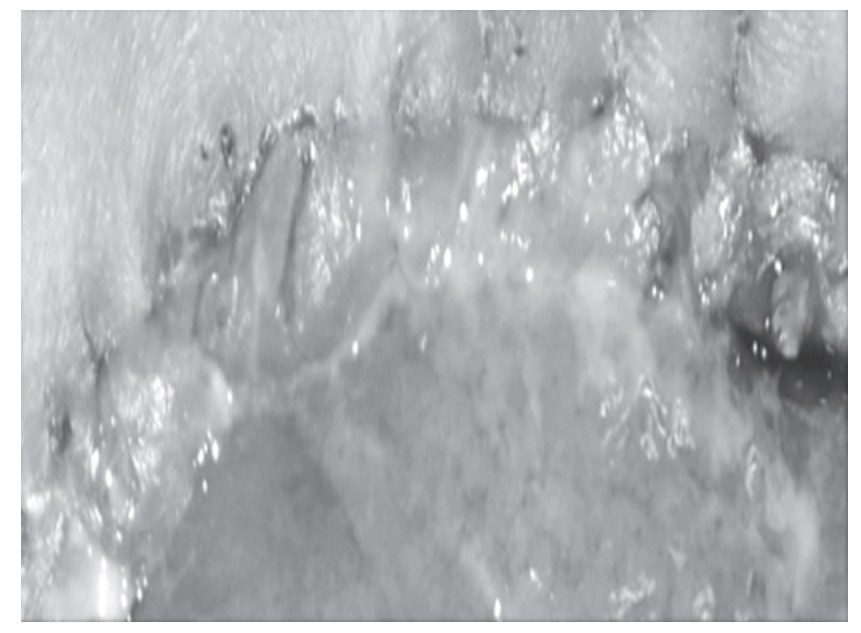

Figura 4. Detalle de herida en fase inflamatoria.

Posteriormente, se produce el acúmulo de monocitos que reemplazan a los neutrófilos, estimulados por factores quimiotácticos, (fragmentos de colágeno, elastina, fibronectina, trombina enzimáticamente activa, TGF $\beta 1$, kalikreína y productos de degradación de la 
matriz). Los monocitos de los vasos, al migrar al tejido se transforman en macrófagos y se unen a proteínas de la matriz extracelular mediante receptores de integrina, promoviendo la fagocitosis. Así se produce la descontaminación del foco y el desbridamiento autolítico facilitado por la liberación de enzimas como las colagenasas ${ }^{(24,25)}$.

Las endotoxinas bacterianas también activan la liberación de Interleucina 1 (IL-1) por parte de los macrófagos, que a su vez estimula la liberación de Interleucina (IL-8) que atraerá más neutrófilos, aumentando así la destrucción tisular.

Los macrófagos, una vez unidos a la matriz extracelular, sufren un cambio fenotípico, y pasan de comportarse como células inflamatorias a comportamiento de células reparadoras, que liberan citoquinas y factores de crecimiento (TGF $\alpha$ y $\beta$, PDGF, FGF y IGF-1) con un importante papel en la neoformación tisular; siendo los procesos descritos los que permiten la inducción de la angiogénesis y la formación de tejido de granulación, preparando el lecho de la lesión para la siguiente etapa fisiológica ${ }^{(11,12)}$.

\section{FASE III - PROLIFERATIVA O DE GRANULACIÓN}

Los fibroblastos constituyen las células más importantes en la producción de matriz dérmica, llegan a la herida desde músculo, tendón, fascia y una vez en el lecho de la lesión, migran con movimientos activos sobre una matriz laxa de fibronectina, para ello el PDGF hace que exprese receptores de integrina $\alpha 1$ y $\alpha 5$, posibilitando la migración e interacción con los demás factores de crecimiento. La hipoxia en el centro de la herida, favorece la liberación de factores de crecimiento estimulantes de la proliferación de fibroblastos (TGF $\beta 1$, PDGF, FGF, EGF y VEGF) ${ }^{(26,27)}$. Para movilizarse a través de la matriz de fibrina, se requiere un sistema proteolítico que facilita el desplazamiento celular, compuesto por enzimas derivadas de fibroblastos, proteasas séricas (plasmina y plasminógeno del suero, activador del plasminógeno) y colagenasas (MMP-1 o metaloproteinasa de la matriz; MMP2 o gelatinasa y MMP-3 o estromalisina). El PDGF estimula la liberación de estas proteínas del fibroblasto mientras que el TGF $\beta$ induce la secreción de inhibidores de las proteinasas, controlando así la degradación de la matriz $(28,29)$ (figura 5).

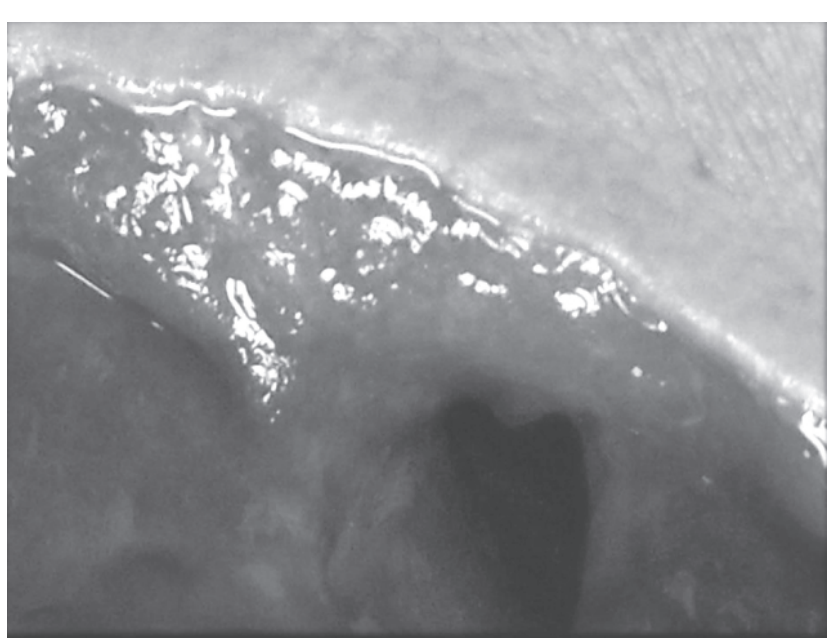

Figura 5. Detalle de herida en fase de granulación.

Con la migración de fibroblastos estos depositan una neomatriz provisional de fibronectina y ácido hialurónico estimulados por citoquinas y factores de crecimiento (TGF $\beta$, PDGF, TNF, FGF, IL1 e IL4) para comenzar a sintetizar la matriz de colágeno (tipos I, III y VI) y una vez que se depositó una suficiente cantidad, cesa la producción, debido a que el INF $\gamma$ y la misma matriz inhiben la proliferación de fibroblastos y la síntesis de colágeno ${ }^{(30)}$. La angiogénesis y la formación de tejido de granulación se inician simultáneamente con la fibroplasia. Los vasos sanguíneos adyacentes a la lesión emiten yemas capilares, en cuyo extremo se encuentran las células endoteliales, que sufren un cambio fenotípico que les permite proyectar pseudópodos a través de las membranas basales fragmentadas y migrar al espacio perivascular; en ésta proliferación endotelial tiene un papel especial el factor de crecimiento vascular-endotelial (VEGF) y las angiopoyetinas (Ang). La Ang 2 interactúa con un receptor de las células endoteliales (Tie 2), haciéndolas más laxas y disminuyendo el contacto de éstas con la matriz para favorecer la acción del $\operatorname{VEGF}^{(31,32)}$.

El TGF $\beta$ estimula la síntesis de fibronectina y proteoglicanos para constituir la matriz provisional, y a su vez facilita la migración celular e induce el fenotipo de célula endotelial adecuado para la formación de tubos capilares ${ }^{(33)}$ (figura 6).

La proteína acídica y rica en cisteína de la matriz celular (SPARC) liberada por los fibroblastos y macrófagos, junto a la trombospondina y la tenascina son consideradas proteínas antiadhesivas ya que desestabilizan las interacciones célula-matriz, favoreciendo la angiogénesis. Al mismo tiempo la disminución de la tensión de O2, esti- 


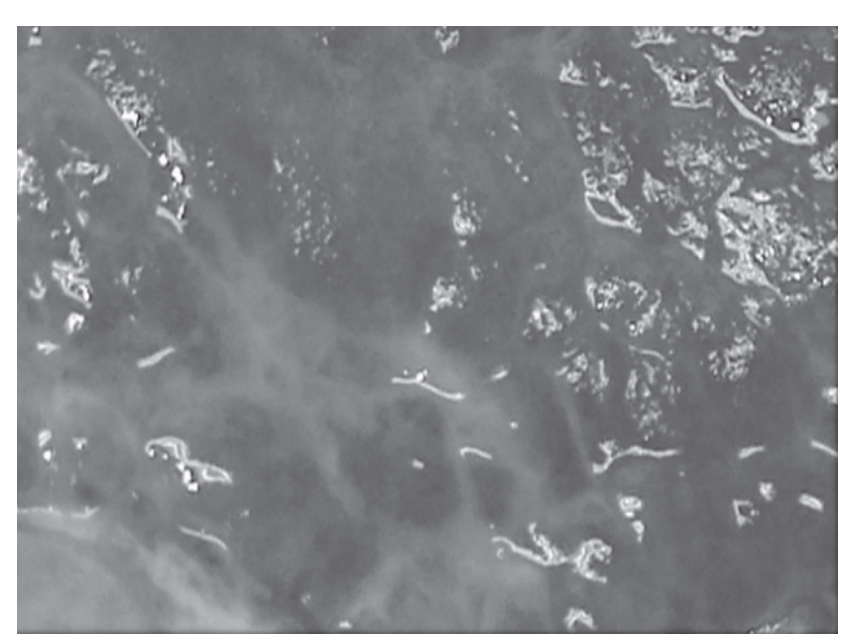

Figura 6. Detalle de angiogénesis en lecho de herida durante la fase de granulación.

mula a los macrófagos para que produzcan y secreten factores angiogénicos, ayudado también por la migración de las células endoteliales los cuales forman brotes capilares que se dividen en sus extremos y luego se unen formando asas y dan origen a los plexos capilares ${ }^{(26)}$.

Después del cese de los estímulos angiogénicos, los capilares sufren una regresión por múltiples factores, entre los cuales se encuentran la tumefacción mitocondrial en las células endoteliales de los extremos distales de los capilares, la adherencia plaquetaria a las células endoteliales y la ingestión de los capilares necrosados por los macrófagos $^{(34,35)}$.

Por último se produce el reclutamiento de las células periendoteliales (pericitos y células de músculo liso) que van a estabilizar los vasos recién formados. Este proceso se realiza por la unión de la Ang1 al receptor Tie 2, aumentando el contacto de éstas con la matriz. Otros receptores celulares que intervienen son los de integrina, en especial el avB3, esencial para la formación y mantenimiento de los nuevos vasos ${ }^{(36,37)}$.

\section{FASE IV - EPITELIZACIÓN}

Para que se lleve a cabo la epitelización de la herida, los queratinocitos deben migrar desde los bordes de la herida o desde los anexos remanentes con el fin de restablecer la barrera cutánea, dicha migración se produce gracias a cambios en su fenotipo que consiste en la pérdida del aparato de adhesión gracias a la retracción de los tonofilamentos y disolución de los desmosomas; adquisición del aparato motor por el desarrollo de filamentos de actina y la proyección de lamelopodios hacia la herida; y la expresión de citoqueratina 6 y 16, las cuales son marcadores del estado activo; estos procesos conllevan a la pérdida de unión de las células epidérmicas entre sí, a la membrana basal y a la dermis subyacente, permitiendo su migración ${ }^{(38)}$ (figura 7).

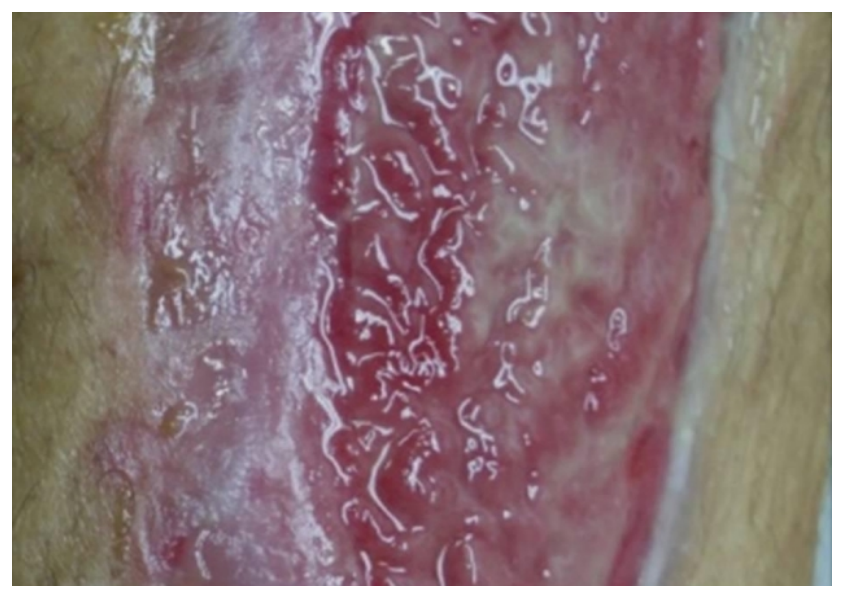

Figura 7. Detalle de herida en fase de epitelización.

Este ciclo de activación del queratinocito comienza con la IL-1, que lo transforma en célula hiperproliferativa y migratoria, dicha actividad la realiza sobre una matriz rica en fibronectina y mediada por receptores de superficie integrínicos (a 5- $\beta 1$ ) y TGF $\beta$. Luego la migración será sobre la matriz definitiva rica en colágeno, mediada por receptores de superficie colagénicos (a 2- $\beta 1$ ) y la liberación de TGF $\alpha$ /EGF; para que se realice este proceso, en la membrana basal desaparecen la laminina y el colágeno de tipo IV. La proliferación ocurre en forma superpuesta a la migración, mientras las células epiteliales migran a través de la herida, las células proximales proliferan por el estímulo de mediadores solubles (EGF/TGF $\alpha$, PDGF/ FGF, etc.) y al "efecto borde" (ausencia de células vecinas en aposición que dispararía el estímulo proliferativo en los márgenes de la herida) ${ }^{(39,40)}$.

Para que el queratinocito finalice su proceso de migración y proliferación existen varias señales: el INF $\gamma$ producido por las células inflamatorias lo estimula a expresar citoqueratina 17 , que lo convierte en contráctil y facilita la reorganización de la matriz de la membrana basal provisoria y el TGF $\beta$ estimula la producción de queratinas K5 y K14 que lo convierten en una célula basal para iniciar nuevamente la diferenciación y la reparación de la membrana basal con el nuevo depósito de laminina, también es una señal que le indica que la herida ya está reparada y no hay necesidad de migrar $(20,41,42)$. 
De igual forma es importante aclarar que en la piel sana, los queratinocitos no están en contacto con los colágenos de la membrana basal (IV y VII) o de la dermis (I, III y V) que son activadores de la migración y sí lo están con la laminina de la lámina lúcida, la cual inhibe la migración de éstos ${ }^{(43)}$.

\section{FASE V - REMODELACIÓN O DE CONTRACCIÓN}

Es la última etapa, comienza al mismo tiempo que la fibroplasia y continúa por meses. La célula principal es el fibroblasto que produce fibronectina, ácido hialurónico, proteoglicanos y colágeno durante la fase de reparación, los cuales sirven como base para la migración celular y soporte tisular. Con el tiempo la fibronectina y el ácido hialurónico desaparecen por acción de proteasas y hialuronidasas respectivamente ${ }^{(44)}$.

Posteriormente, el colágeno tipo III es reemplazado por el de tipo I, siendo éste más estable y similar al original. La degradación del primer colágeno se debe a la acción de las metaloproteinasas de la matriz (colagenasas, gelatinasas y estromalisinasas), cuya actividad depende de los iones de zinc y que son estimuladas por factores de crecimiento y la matriz extracelular ${ }^{(45,46)}$.

Como se ha descrito, los fibroblastos sufren una serie de cambios fenotípicos. Primero adoptan un fenotipo migratorio, luego un fenotipo profibrótico (mientras producen colágeno I, III y VI) y posteriormente, adoptan el fenotipo de miofibroblasto, rico en microfilamentos de actina en el lado citoplasmático de la membrana y establece uniones célula-célula (adherentes) y uniones con la matriz extracelular a través de receptores integrínicos, este colágeno neoformado se une a través de enlaces covalentes cruzados con haces del borde de la herida y con haces de la dermis adyacente, estas uniones crean una red a través de la herida y así la tracción que realizan los fibroblastos a la matriz pericelular se puede transmitir dando como resultado una contracción coordinada, estimulada por el TGF $\beta$, la angiotensina, las prostaglandinas, la bradiquinina y la endotelina. En el último día de la cicatrización los fibroblastos inician su proceso de apoptosis, estableciéndose una transición de una cicatriz rica en fibroblastos y tejido de granulación, a una cicatriz acelular ${ }^{(47,48)}$.

Al final del proceso la actividad celular disminuye y el tejido conjuntivo cicatrizal se torna rico en colágeno, pobre en células y vasos, sin folículos pilosos y sin glándulas sudoríparas ni sebáceas. La dermis recupera la composición previa a la lesión y alcanza una resistencia máxima del 70\% comparada con el tejido previo y la reparación de la herida se considera finalizada; en una herida de espesor completo hay reducción del tamaño en un $40 \%$ respecto del tamaño original $^{(49,50)}$ (figura 8).

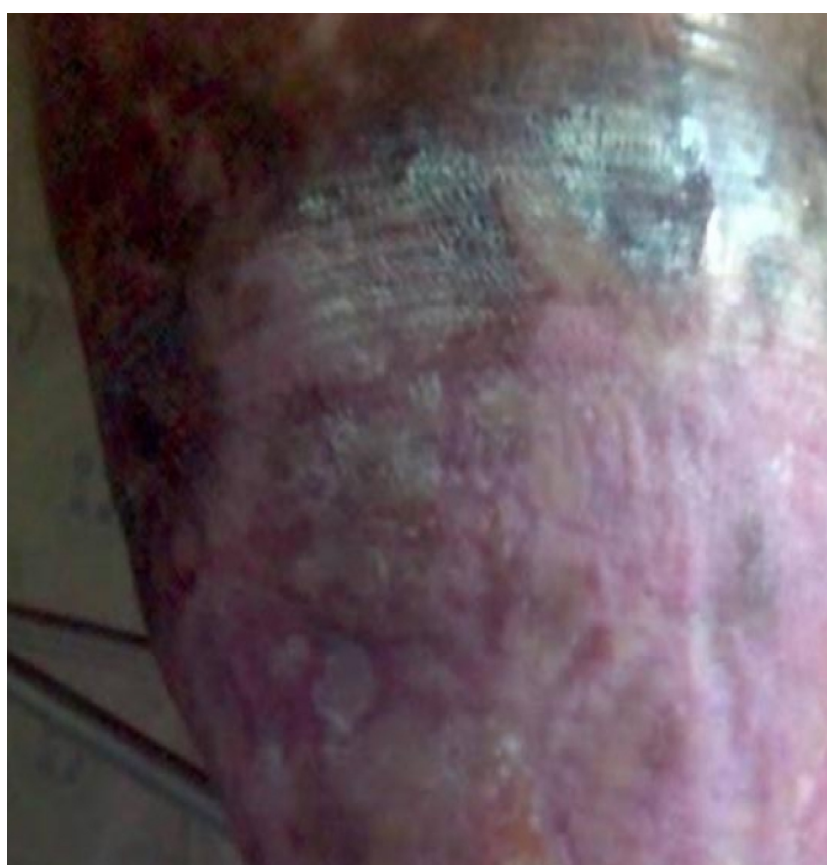

Figura 8. Detalle de herida en fase de contracción.

\section{CONCLUSIONES}

Una herida es una agresión a la integridad de la cobertura cutánea y de las estructuras subyacentes. Las lesiones de los tejidos blandos pueden aparecer de manera aislada o en el contexto del paciente politraumatizado; la cicatrización cutánea es un proceso reparativo complejo que conduce a la regeneración del epitelio y el reemplazo de la dermis por un tejido fibroso constituido por colágeno con características diferentes al normal. Las nuevas fibras son más cortas y desorganizadas, por lo que la cicatriz nunca presenta la fuerza tensora de la piel ilesa. A este proceso de reparación de las heridas, se le ha dividido de manera didáctica y para facilitar su comprensión y estudio en fases, las cuales ocurren de manera secuencial pero se superponen en el tiempo, siendo coordinadas por mediadores humorales derivados de las células que participan en dicha reparación y comprenden: "hemostasia", "inflamatoria", "proliferativa" o de "granulación", de "epitelización" y de "remodelación" (figura 9). 


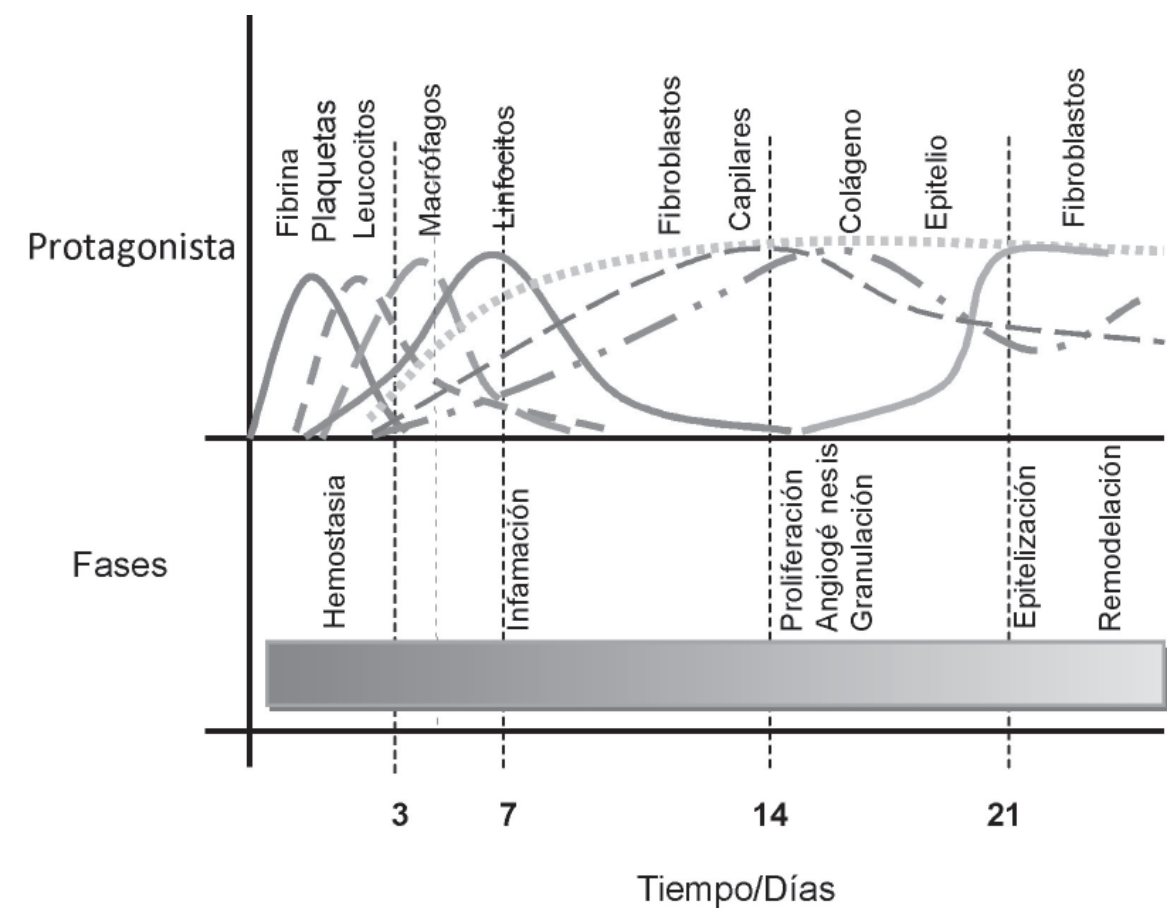

Figura 9. Fases de la cicatrización y su respectivo protagonista.

\section{AGRADECIMIENTOS}

Especiales y sinceros agradecimientos a Luis Eduardo Sanabria Rivera M.D. Cirujano General - Intensivista, Coordinador del Departamento de Cirugía General del Hospital Universitario de Neiva E.S.E., dado que gracias a su apoyo y diligencia administrativa académica y asistencial, que fueron, son y siguen siendo cruciales para vivir mi realidad como líder nacional en cicatrización y mantener una proyección personal exponencial; de igual forma a Tatiana Solano Nivia mi esposa, por su proactivo acompañamiento durante la realización del presente texto.

\section{REFERENCIAS}

1. Porter, R. 2004. Breve historia de la medicina. Tercera edición. Barcelona: Ediciones Taurus 6:100-105.

2. Harvey, G. 1942. Historia de la cirugía. Segunda edición. Barcelona: Editorial Iberia 5:456-470.

3. Krasner, D., Sibbald, G. 2002. Chronic wound care. Third edition. San Diego: Appleton and Lange 12:120-140.

4. Rivington, L.G. 2002. Hanging wet-to-dry dressings out to dry, advanced in skin and wound care. Adv Wound Care 15:279-284.
5. Lazaurus, G.S. 1994. Definitions and guidelines for assessment of wounds and evaluation of healing. Wounds 130:489.

6. Bradley, U., Cullum, N., Nelson, E.A. 1999. Systematic reviews of wound care management dressings and topical agents used in the healing of chronic wounds. Health Techn Asses 3:1-18.

7. Hartoch, R.S. 2007. Emergency management of chronic wounds. Emerg Med Clin North Am 25(1):203-221.

8. Clark, R.A.F., ed. 1996. The molecular and cellular biology of wound repair. 2nd ed. New York: Plenum Press 1996.

9. Kirsner, R., Eaglstein, W. 1993. El proceso de curación de las heridas. Clínicas Dermatológicas. Ed. Interamericana, Madrid 11:653-662.

10. Schiro, J.A., Chan, B.M.C., Roswit, W.T. et al. 1991. Integrin a2b1 (VLA-2) mediates reorganization and contraction of collagen matrices by human cells. Cell 67:403-10.11

11. Montesano, R, Orci, L. 1988. Transforming growth factor-b stimulates collagen- matrix contraction by fibroblasts: implications for wound healing. Proc Natl Acad Sci U S A 85:4894-4897.

12. Shah, M., Foreman, D.M., Ferguson, M.W.J. 1995. Neutralisation of TGF-b1 and TGF-b2 or 
exogenous addition of TGF-b3 to cutaneous rat wounds reduces scarring. J Cell Sci 108:9851002.

13. Brown, L.F., Yeo, K.T., Berse, B. et al. 1992. Expression of vascular permeability factor (vascular endothelial growth factor) by epidermal keratinocytes during wound healing. J Exp Med 176:1375-1379.

14. Clark, R.A.F., Quinn, J.H., Winn, H.J., Lanigan, J.M., Dellepelle, P, Colvin, R.B. 1982. Fibronectin is produced by blood vessels in response to injury. J Exp Med 156:646-651.

15. Leibovich, S.J., Ross, R. 1975. The role of the macrophage in wound repair: a study with hydrocortisone and antimacrophage serum. Am J Pathol 78:71-100.

16. Riches, D.W.H. 1996. Macrophage involvement in wound repair, remodeling, and fibrosis. In: Clark, R.A.F., ed. The molecular and cellular biology of wound repair. 2nd ed. New York: Plenum Press 95-141.

17. Paladini, R.D., Takahashi, K., Bravo, N.S., Coulombe, P.A. 1996. Onset of re-epithelialization after skin injury correlates with a reorganization of keratin filaments in wound edge keratinocytes: defining a potential role for keratin 16. J Cell Biol 132:381-397.

18. Goliger, J.A., Paul D.L. 1995. Wounding alters epidermal connexin expressionand gap junction-mediated intercellular communication. Mol Biol Cell 6:1491-1501.

19. Clark, R.A.F. 1990. Fibronectin matrix deposition and fibronectin receptor expression in healing and normal skin. J Invest Dermatol 94:Suppl:128S-134S.

20. Larjava, H., Salo, T., Haapasalmi, K., Kramer, R.H., Heino, J. 1993. Expression of integrins and basement membrane components by wound keratinoctyes. J Clin Invest 92:14251435.

21. Hunt, TK, ed. 1980. Wound healing and wound infection: theory and surgical practice. New York: Appleton-Century-Crofts.

22. Gray, A.J., Bishop, J.E., Reeves, J.T., Laurent, G.J. 1993. Aa and Bb chains of fibrinogen stimulate proliferation of human fibroblasts. J Cell Sci 104:409-413.

23. Xu, J., Clark R.A.F. 1996. Extracellular matrix alters PDGF regulation of fibroblast integrins. J Cell Biol 132:239-249.

24. Vaalamo, M., Mattila, L., Johansson, N. et al. 1997. Distinct populations of stromal cells express collagenase-3 (MMP-13) and collagenase-1 (MMP-1) in chronic ulcers but not in normally healing wounds. J Invest Dermatol 109:96-101.

25. Welch, M.P., Odland, G.F., Clark, R.A.F. 1990. Temporal relationships of F-actin bundle formation, collagen and fibronectin matrix assembly, and fibronectin receptor expression to wound contraction. J Cell Biol 110:133-145.

26. Detmar, M., Brown, L.F., Berse, B. et al. 1997. Hypoxia regulates the expression of vascular permeability factor/vascular endothelial growth factor (VPF/VEGF) and its receptors in human skin. J Invest Dermatol 108:263-268.

27. Nissen, N.N., Polverini, P.J., Koch, A.E., Volin, M.V., Gamelli, R.L., DiPietro, L.A. 1998. Vascular endothelial growth factor mediates angiogenic activity during the proliferative phase of wound healing. Am J Pathol 152:1445-1452.

28. Brooks, P.C., Clark, R.A.F., Cheresh, D.A. 1994. Requirement of vascular integrin avb3 for angiogenesis. Science 264:569-571.

29. Pintucci, G., Bikfalvi A., Klein S., Rifkin, D.B. 1996. Angiogenesis and the fibrinolytic system. Semin Thromb Hemost 22:517-524.

30. Clark, R.A.F., Folkvord J.M., Hart C.E., Murray M.J., McPherson, J.M. 1989. Platelet isoforms of platelet-derived growth factor stimulate fibroblasts to contract collagen matrices. J Clin Invest 84:1036-1040.

31. Iruela-Arispe, M.L., Dvorak, H.F. 1997. Angiogenesis: a dynamic balance of stimulators and inhibitors. Thromb Haemost 78:672-677.

32. Risau, W. 1997. Mechanisms of angiogenesis. Nature 386:671-674.

33. Babu, M., Diegelmann, R., Oliver, N. 1992. Keloid fibroblasts exhibit an altered response to TGF-beta. J Invest Dermatol 99:650-655.

34. Desmouliere, A., Redard, M, Darby, I, Gabbiani, G. Apoptosis mediates the decrease in cellularity during the transition between granulation tissue and scar. Am J Pathol 1995;146:56-66.

35. Folkman, J., D'Amore, P.A. 1996. Blood vessel formation: what is its molecular basis? Cell ;87:1153-1155.

36. Madri, J.A., Sankar S., Romanic, A.M. 1996. Angiogenesis. In: Clark, RAF, ed. The molecular and cellular biology of wound repair. 2nd ed. New York: Plenum Press 355-371. 
37. Folkman, J. 1997. Angiogenesis and angiogenesis inhibition: an overview. EXS 79:1-8.

38. Gabbiani, G., Chaponnier, C., Huttner, I. 1978. Cytoplasmic filaments and gap junctions in epithelial cells and myofibroblasts during wound healing. J Cell Biol 76:561-568.

39. Clark, R.A.F., Ashcroft, G.S., Spencer, M.J., Larjava, H., Ferguson, M.W.J. 1996. Reepithelialization of normal human excisional wounds is associated with a switch from avb5 to avb6 integrins. Br J Dermatol 135:46-51.

40. Pilcher, B.K., Dumin, J.A., Sudbeck, B.D., Krane, S.M., Welgus, H.G., Parks, W.C. 1997. The activity of collagenase- 1 is required for keratinocyte migration on a type I collagen matrix. J Cell Biol 137:1445-1457.

41. Werner, S., Smola, H., Liao, X. et al. 1994. The function of KGF in morphogenesis of epithelium and reepithelialization of wounds. Science 266:819-822.

42. Guo, N., Krutzsch, H.C., Inman, J.K., Roberts, D.D. 1997. Thrombospondin 1 and type I repeat peptides of thrombospondin 1 specifically induce apoptosis of endothelial cells. Cancer Res 57:1735-1742.

43. Greiling, D., Clark, R.A.F. 1997. Fibronectin provides a conduit for fibroblast transmigration from collagenous stroma into fibrin clot provisional matrix. J Cell Sci 110:861-870.

44. Toole, BP. 1991. Proteoglycans and hyaluronan in morphogenesis and differentiation. In: Hay
ED, ed. Cell biology of extracellular matrix. 2nd ed. New York: Plenum Press 305-341.

45. Woodley, D.T., Yamauchi, M., Wynn, K.C., Mechanic, G., Briggaman, R.A. 1991. Collagen telopeptides (cross-linking sites) play a role in collagen gel lattice contraction. J Invest Dermatol 97:580-585.

46. Madlener, M., Parks, W.C., Werner, S. 1998. Matrix metalloproteinases (MMPs) and their physiological inhibitors (TIMPs) are differentially expressed during excisional skin wound repair. Exp Cell Res 242:201-210.

47. Bailey, A.J., Bazin, S., Sims, T.J., Le Lous, M., Nicholetis, C., Delaunay, A. 1975. Characterization of the collagen of human hypertrophic and normal scars. Biochim Biophys Acta 405:412-421.

48. Tredget, E.F., Nedelec, B., Scott, P.G., Ghahary, A. 1997. Hypertrophic scars, keloids, and contractures: the cellular and molecular basis for therapy. Surg Clin North Am 77:701-730.

49. Machesney, M., Tidman, N., Waseem, A., Kirby, L., Leigh, I. 1998. Activated keratinocytes in the epidermis of hypertrophic scars. Am J Pathol 152:1133-1141.

50. Zhang, K., Garner, W., Cohen, L, Rodriguez., J, Phan, S. 1995. Increased types I and III collagen and transforming growth factor-beta $1 \mathrm{mRNA}$ and protein in hypertrophic burn scar. J Invest Dermatol 104:750-754. 